\title{
Herbal and antibiotic resistance of Aeromonas bacteria isolated from cultured fish in Egypt and Malaysia.
}

\begin{abstract}
Motile Aeromonad septicemia is the main devastating disease in cultured fish and caused mainly by Aeromonas hydrophila. Development of pathogenic bacterial resistance caused by the excessive use of chemotherapeutics is the main disadvantage of antibiotic application. Thus, the sensitivity of certain commercial antibiotics and common herbs was evaluated against pathogenic A. hydrophila, A. sobria and A. caviae, isolated from Malaysian and Egyptian cultured fish, mainly tilapia. A suspension of freshly cultured isolates was prepared and spread over the Muller's Hinton agar plates to study their sensitivity to both antibiotics and herbs. Double-fold dilution was used to determine the Minimal Inhibitory Concentration (MIC) for the effective herbs at 100, 50, 25, 12.5 and 6.25\%. Results revealed high resistance of the 6 tested Aeromonas isolates against most of the screened antibiotics except Ciprofloxacin and Gentamicin. Regarding herbal sensitivity, only Origanum vulgare showed an efficacy and inhibition zone against all isolates except A. hydrophila isolated from cultured tilapia in Egypt which exhibited resistance to that herb. The MIC ranged from 25-55\% for the Egyptian isolates (25\% for A. caviae and 55\% for A. sobria) and 24-30\% for the Malaysian isolates (24\% for A. hydrophila, $25 \%$ for A. caviae and $30 \%$ for A. sobria). This study recommends the mandate of effective vaccine development against A. hydrophila to protect cultured fish from that pathogen due to its high resistance for both herbs and antibiotics.
\end{abstract}

Keyword: Aeromonas hydrophila; A. Caviae; A. Sobria; Bacterial resistance; Egypt; Malaysia. 